\title{
Maternal hyperoxygenation in congenital heart disease
}

\author{
Fu-Tsuen Lee ${ }^{1,2}$, Davide Marini ${ }^{2}$, Mike Seed $^{2,3}$, Liqun Sun $^{2}$ \\ ${ }^{1}$ Department of Physiology, Faculty of Medicine, University of Toronto, Toronto, Canada; ${ }^{2}$ Division of Cardiology, Department of Paediatrics, \\ Hospital for Sick Children, University of Toronto, Toronto, Canada; ${ }^{3}$ Department of Diagnostic Imaging, Hospital for Sick Children, University of \\ Toronto, Toronto, Canada \\ Contributions: (I) Conception and design: All authors; (II) Administrative support: None; (III) Provision of study materials or patients: None; (IV) \\ Collection and assembly of data: FT Lee; (V) Data analysis and interpretation: FT Lee; (VI) Manuscript writing: All authors; (VII) Final approval of \\ manuscript: All authors. \\ Correspondence to: Liqun Sun, MD, PhD. Division of Cardiology, Department of Paediatrics, Hospital for Sick Children, University of Toronto, 555 \\ University Avenue, Toronto, Ontario M5G 1X8, Canada. Email: liqun.sun@sickkids.ca.
}

\begin{abstract}
The importance of prenatal diagnosis and fetal intervention has been increasing as a preventative strategy for improving the morbidity and mortality in congenital heart disease (CHD). The advancements in medical imaging technology have greatly enhanced our understanding of disease progression, assessment, and impact in those with CHD. In particular, there has been a growing focus on improving the morbidity and mortality of fetuses diagnosed with left-sided lesions. The disruption of fetal hemodynamics resulting from poor structural developmental of the left outflow tract during cardiogenesis is considered a major factor in the progressive lethal underdevelopment of the left ventricle (LV). This positive feedback cycle of inadequate flow and underdevelopment of the LV leads to a disrupted fetal circulation, which has been described to impact fetal brain growth where systemic outflow is poor and, in some cases, the fetal lungs in the setting of a restrictive interatrial communication. For the past decade, maternal hyperoxygenation $(\mathrm{MH})$ has been investigated as a diagnostic tool to assess the pulmonary vasculature and a therapeutic agent to improve the development of the heart and brain in fetuses with CHD with a focus on left-sided cardiac defects. This review discusses the findings of these studies as well as the utility of acute and chronic administration of MH in CHD.
\end{abstract}

Keywords: Fetal; maternal hyperoxygenation (MH); congenital heart disease (CHD); diagnosis; therapy

Submitted Aug 03, 2020. Accepted for publication Aug 27, 2020.

doi: $10.21037 / \mathrm{tp}-20-226$

View this article at: http://dx.doi.org/10.21037/tp-20-226

\section{Introduction}

Congenital heart disease (CHD) is the most common birth defect, affecting 7 to 9 per 1,000 newborns (1). About $25 \%$ of these are diagnosed with critical CHD and have a $75.2 \%$ one-year survival rate when compared with $97.1 \%$ in non-critical CHDs (2). Those with underdeveloped left-sided cardiac structures have the lowest one-year survival rate at $17.4 \%$ despite improvements in prenatal diagnosis, corrective surgery, and postnatal management (3). Moreover, children with CHD, especially critical CHD, are at increased risk for neurodevelopmental impairment (4). The recent advancements in fetal imaging have led to a greater understanding of the human fetal circulation and disease progression regarding the heart, lungs, and brain in CHD during fetal development (5-9). Accordingly, preventative approaches during the prenatal period may have considerable benefits for improving these outcomes. Maternal hyperoxygenation (MH) administration during pregnancy has been previously investigated as a diagnostic tool in various conditions (10-15) or as a therapeutic agent to improve fetal development in fetal growth restriction (16). For the past decade, $\mathrm{MH}$ has been investigated in CHD with a focus on left-sided cardiac defects as a diagnostic tool and therapeutic agent to improve developmental outcomes of the lungs, heart, and brain. This review discusses these findings and the utility of acute and chronic administration of $\mathrm{MH}$ in CHD (Table 1). 
Table 1 Summary of maternal hyperoxygenation in congenital heart disease

\begin{tabular}{|c|c|c|c|c|}
\hline Reference & Diagnosis & Oxygen delivery & Protocol & Goals \\
\hline Kohl et al. [2010] & Hypoplastic heart structures & Chronic & $\begin{array}{l}50-60 \% \text { eFiO } 2,3 \times 4 \text { hours of } \\
\mathrm{MH} / \text { day }\end{array}$ & $\begin{array}{l}\text { Improve cardiac structural } \\
\text { growth }\end{array}$ \\
\hline Kohl et al. [2011] & $\begin{array}{l}\text { Foramen ovale closure, aortic } \\
\text { isthmus hypoplasia, turbulent } \\
\text { distal arch flow }\end{array}$ & Chronic & $45 \% \mathrm{eFiO}_{2}, 3 \times 4$ hours of $\mathrm{MH} /$ day & $\begin{array}{l}\text { Improve aortic isthmus } \\
\text { dimensions }\end{array}$ \\
\hline Zeng et al. [2016] & Isolated coarctation & Chronic & $45 \% \mathrm{eFiO}_{2}, 2 \times 3$ hours of $\mathrm{MH} /$ day & $\begin{array}{l}\text { Improve left-sided cardiac } \\
\text { structural growth }\end{array}$ \\
\hline $\begin{array}{l}\text { Channing et al. } \\
\text { [2015] }\end{array}$ & $\begin{array}{l}\text { Fetal atrial septum aneurysm } \\
\text { with small LV }\end{array}$ & Acute & $60 \% \mathrm{eFiO}_{2}$, assessed after $10 \mathrm{~min}$ & Improve left-heart filling \\
\hline $\begin{array}{l}\text { Porayette et al. } \\
\text { [2016] }\end{array}$ & $\mathrm{CHD}$ & Acute & $70 \% \mathrm{eFiO}_{2}$, assessed after $10 \mathrm{~min}$ & $\begin{array}{l}\text { Validate CMR in fetuses with } \\
\mathrm{CHD}\end{array}$ \\
\hline Borik et al. [2015] & $\begin{array}{l}\text { Borderline LVH with retrograde } \\
\text { flow across the aortic isthmus }\end{array}$ & Acute & $70 \% \mathrm{eFiO}_{2}$, assessed after $20 \mathrm{~min}$ & $\begin{array}{l}\text { Fetal circulatory assessment } \\
\text { in } \mathrm{CHD}\end{array}$ \\
\hline $\begin{array}{l}\text { Szwast et al. } \\
\text { [2018] }\end{array}$ & HLHS variants & Acute & $60 \% \mathrm{eFiO}_{2}$, assessed after $10 \mathrm{~min}$ & $\begin{array}{l}\text { Assess cerebrovascular } \\
\text { response }\end{array}$ \\
\hline
\end{tabular}

HLHS, hypoplastic left heart syndrome; RAS, restrictive atrial septum; IAS, intact atrial septum; HLH, hypoplastic left heart; LHH, left heart hypoplasia; LV, left ventricle; CHD, congenital heart disease; LSOL, left-sided obstructive lesion; RSOL, right-sided obstructive lesion; d-TGA, dextro-transposition of the great arteries; CMR, cardiac magnetic resonance; $\mathrm{LVH}$, left ventricular hypoplasia; eFiO ${ }_{2}$, effective fraction of inspired oxygen.

\section{Fetal circulation and mechanism of action of MH}

The fetal heart operates on a unique parallel circuit to divert a large percentage of blood away from the relatively inactive fetal lungs. In the normal fetal circulation, substrate rich blood, consisting mainly of oxygen and glucose from the placenta, bypasses the liver via the ductus venosus and flows across the foramen ovale and into the left side of the heart (17). This mechanism known as fetal streaming plays two crucial purposes: (I) to preferentially stream substrate rich blood to the heart and brain $(5,17,18)$, and (II) to provide adequate blood flow to the left heart to augment blood flow-directed remodelling required for normal cardiac morphogenesis $(5,19)$.

In left-sided CHD, cardiac structures of the left heart are underdeveloped and result in disruptions to this circulation. The extent of the fetal circulatory disruptions will depend on the severity of disease. In most cases, the left ventricle (LV) is hypoplastic and is described as a progressively evolving disease involving the left ventricular outflow tract, aortic valve, and aorta (Figure 1) (19). Mild 

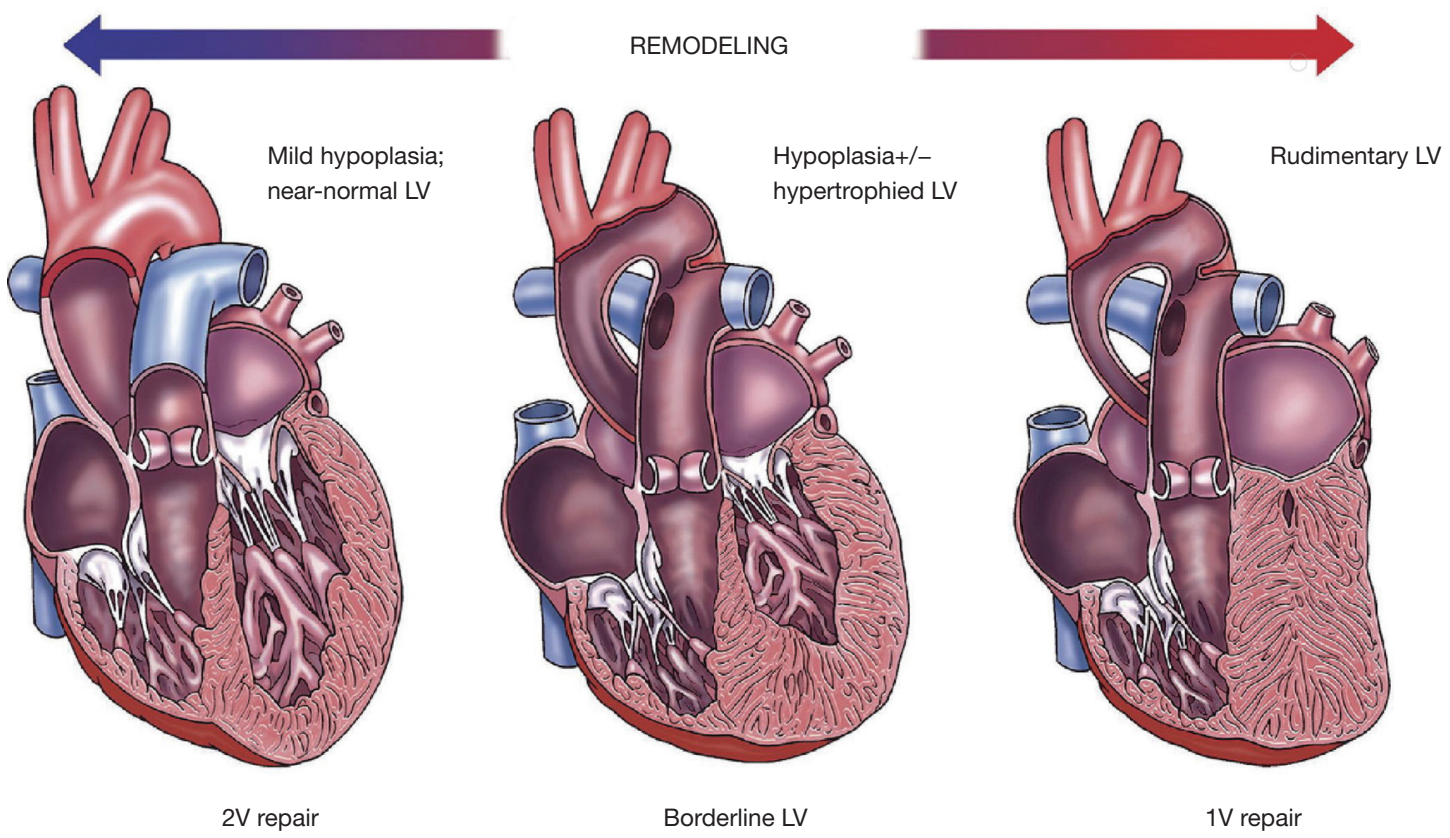

Figure 1 Spectrum of left ventricular (LV) hypoplasia as a result of abnormal blood flow-directed remodelling secondary to primary LV outflow obstructive lesions occurring during cardiogenesis. Mild forms of LV hypoplasia are supportive for biventricular repair whereas severe forms of LV hypoplasia require single ventricle palliation repair [image adapted with permission from (19)].

forms of left ventricular hypoplasia (LVH) may result in minor intracardiac mixing in the right atrium and reduced prograde flow to the brain. On the other spectrum, severe forms such as hypoplastic left heart syndrome (HLHS) with mitral and aortic atresia, there is complete mixing of the substrate rich placental blood and substrate deficient systemic return in the right atrium, resulting in relatively diluted oxygen and nutrient blood delivered through the ductus arteriosus (DA) and retrograde across the aortic isthmus (i.e., hypoperfusion) towards the fetal brain (19). This has important implications for other fetal organs such as the brain especially when it is important that substrate delivery meets the metabolic demands during critical windows of organ development (17).

Administration of $\mathrm{MH}$ has two general mechanisms of action in the fetus. Firstly, $\mathrm{MH}$ can cause an increase in pulmonary blood flow. The fetal pulmonary arteries (PAs) begin to develop a layer of smooth muscle at 21 to 26 gestational weeks (GW) (20), which vasodilates upon endothelial-derived vasodilators such as nitro oxide which is synthesized during hyperoxemia (21). In the human fetus, a decrease in pulmonary arterial vascular resistance (PAVR) in response to $\mathrm{MH}$ has been detected by Doppler ultrasound as early as $24 \mathrm{GW}(22)$ and manifests greater responses as gestation advances (23). This is reflected by the growing total number of PAs and increased vasomotor reactivity leading to a greater increase in pulmonary blood flow in response to hyperoxemia (20). Secondly, $\mathrm{MH}$ can cause an increase in fetal oxygen delivery (24). Taking advantage of these two overarching mechanisms, investigators have used $\mathrm{MH}$ as a diagnostic tool and therapeutic agent focused on left-sided CHD, as explained in the subsequent sections.

\section{MH as a diagnostic tool}

Fetal lung development is a major concern in newborns with HLHS with a restrictive or intact atrial septum (RAS/IAS). In these cases, there is no exit for pulmonary venous egress which leads to left arterial and pulmonary hypertension and eventually, maldevelopment of the fetal lungs (25). In normal maturation of the fetal pulmonary vasculature, pulmonary blood flow is tightly regulated by a balance of pulmonary arterial vasodilation and vasoconstriction mainly via endothelium-derived nitric oxide synthesis and myogenic response, respectively. This protective mechanism is hypothesized to preserve normal pulmonary vascular development (26). A chronic increase in pulmonary blood flow and pressure resulting in pulmonary hypertension 
has been shown to have profound maladaptive changes to the pulmonary apparatus in lamb studies described as arterial hypertrophy and impairment of endothelium nitric oxide-dependent vasodilation $(27,28)$. Fetuses with HLHS with RAS/IAS are expected to undergo maladaptive lung development and lose their pulmonary vasodilatory capacity during late gestation. Histopathological evaluation at autopsy of HLHS infants with RAS/IAS have demonstrated pulmonary arterial hypertrophy, pulmonary vein arterialization, and marked dilatation of the lymphatics $(25,29,30)$. Understanding the state of the pulmonary vasculature may be valuable for treatment strategies.

Szwast et al. and Enzensberger et al. $(31,32)$ have investigated the diagnostic value of acute administration of $\mathrm{MH}(\mathrm{AMH})$ as a provocation test to assess the pulmonary vasodilatory capacity to gauge the degree of pulmonary vasculopathy in fetuses with HLHS and RAS/IAS. In both studies, PA vasoreactivity was assessed at room air and after AMH [ $60 \%$ effective fraction of inspired oxygen $\left(\mathrm{eFiO}_{2}\right)$ for 10 minutes]. Fetuses with HLHS with an open interatrial communication responded to $\mathrm{AMH}$ reflected by a decrease in PAVR (i.e., vasodilation). On the contrary, fetuses with HLHS and RAS/IAS had no significant change in PAVR at later gestation, suggesting injury to the PAs. To illustrate pulmonary vasculopathy progression, fetal echocardiography at $26 \mathrm{GW}$ detected a decrease in PAVR upon AMH. However, there was no significant vasoreactivity to $\mathrm{AMH}$ at $32 \mathrm{GW}$ of the same subject with HLHS and RAS (31).

The diagnostic value based on $\mathrm{AMH}$ testing cannot be understated. AMH testing for vasoreactivity correctly identified fetuses required for immediate atrial intervention at birth. Moreover, Szwast et al. (31) found 2 HLHS fetuses that fit the criteria for RAS (33-35) were vasoreactive upon $\mathrm{AMH}$ in the late third trimester. At birth, these subjects had good oxygen saturations while breathing room air. As a result, $\mathrm{MH}$ can provide important diagnostic value as these cases avoided fetal atrial intervention, which in itself is a risk factor for prematurity and fetal mortality. Fetal atrial septostomy performed in utero in fetuses with HLHS and RAS/IAS is anticipated to decompress the left atrium and improve pulmonary venous egress, thus strengthen fetal lung development for the transition from fetal to neonatal life. However, this method is technically challenging $(36,37)$ and not always successful, with $38 \%$ of cases facing complications and $9.5 \%$ resulting in fetal demise (38). In summary, the lack of pulmonary vasoreactivity in response to AMH illustrates abnormal development of the pulmonary vascular bed (i.e., pulmonary vasculopathy) caused by a restricted or intact atrial septum in HLHS. AMH can be a useful clinical tool for identifying pulmonary vasculopathy in utero and providing diagnostic value in the timing and type of treatment strategies.

\section{MH as a therapeutic tool}

\section{MH for fetal heart development in CHD}

Fetuses with LVH require a series of cardiac surgeries after birth for survival, extensive intensive care, and have poor short- and long-term morbidity extending to other organ systems $(19,39,40)$. The progressive nature of LVH has been attributed to the abnormal or lack of left ventricular pressure and volume loading as a result of primary defects in the left outflow tract originating from basic developmental errors during cardiogenesis $(19,41,42)$. Furthermore, limited or the lack of prograde flow in the ascending aorta has also been implicated in transverse aortic arch hypoplasia and coarctation of the aorta $(43,44)$. Based on the pulmonary vasodilatory response to $\mathrm{MH}$, chronic administration of $\mathrm{MH}(\mathrm{CMH})$ is expected to result in a sustained increase in pulmonary blood flow, pulmonary venous return, and cause improved left-heart filling. This manipulation is expected to augment blood flow directed remodelling of the left heart and improve left heart structural development spanning from the mitral valve to the aortic isthmus. The goal is to minimize LVH progression towards HLHS and promote the $\mathrm{LV}$ for biventricular repair in newborns with $\mathrm{LVH}$ and avoid single ventricle palliation, which is associated with worse life expectancy and higher morbidity and mortality (45).

Five studies have reported the effects of $\mathrm{CMH}$ during the third trimester as a potential therapeutic tool to improve left heart structure growth in utero (46-50).

Kohl et al. (46) was the first to demonstrate two monumental findings of the effects of $\mathrm{CMH}$ on cardiac structural dimensions. First, $\mathrm{MH}$ administration (50-60\% $\mathrm{eFiO}_{2}$ ) for 1 to 2 hours during the third trimester increased blood flow across the pulmonary veins and mitral valve in a cohort comprised mostly of fetuses with hypoplastic left heart structures. During the cardiac loading phase, there was an increase in the mitral valve, ascending aorta, and aortic isthmus dimensions. This is direct evidence $\mathrm{MH}$ administration causes improved left heart filling. The second monumental finding revealed these same fetuses 
who subsequently undergone $\mathrm{CMH}\left(50-60 \% \mathrm{eFiO}_{2}\right.$ for $3 \times 4$ hours of $\mathrm{MH} /$ day) during late-gestation demonstrated improvements in hypoplastic left heart structures which include the left ventricular area, mitral valve diameter, aortic valve diameter, ascending aorta diameter, and aortic isthmus diameter. Although this study had no control groups to serve as comparisons by which the results could have reflected the original course of cardiac development, fetuses with smaller cardiovascular dimensions at the beginning of the therapy had the largest increases in left heart dimensions whereas fetuses with more normal dimensions had smaller increases. A subsequent case report (47) from the same group using $\mathrm{CMH}(45 \%$ $\mathrm{eFiO}_{2}$ for $3 \times 4$ hours of $\mathrm{MH} /$ day) from $36+1 \mathrm{GW}$ for 14 days in a fetus with complete foramen ovale closure and aortic isthmus hypoplasia with turbulent distal arch flow demonstrated significant improvements in aortic isthmus diameter from a $Z$-score of -3.1 at diagnosis to -1.4 at birth. Based on the fetal diagnosis, this patient would have likely gone for postnatal coarctation surgery; however, an aortic arch intervention was not needed, and the newborn was sent home. These findings led to considerable interest in the clinical utility of $\mathrm{CMH}$ as a therapeutic tool for cardiac development in the setting of left-sided CHD.

Zeng et al. $(48,49)$ investigated the therapeutic effects of $\mathrm{CMH}\left(45 \% \mathrm{eFiO}_{2}\right.$ for $2 \times 3$ hours of $\mathrm{MH} /$ day) in fetuses with CoA, who also had underdeveloped left heart structures. One important aspect of this study was the assessment of both cardiac structural dimensions (48) and myocardial function (49) throughout the third trimester. Fetuses with $\mathrm{CoA}$ who underwent $\mathrm{CMH}$ demonstrated an increase in left cardiac dimension $\mathrm{Z}$-scores, which includes the mitral valve, aortic valve, ascending aorta, and aortic isthmus when compared to untreated fetuses with CoA. Furthermore, these $\mathrm{Z}$-scores in the $\mathrm{CMH}$-treated fetuses approached normal values at the end of oxygen therapy whereas the $\mathrm{Z}$-scores of untreated fetuses with CoA remained unchanged since the first assessment. Doppler ultrasound revealed $\mathrm{CMH}$ therapy resulted in a reduced occurrence of abnormal flow (persistent reversed end-diastolic flow) in the aortic isthmus which may have accounted for the decreased frequency of confirmed CoA diagnosis and the need for surgical intervention during the postnatal period when compared to untreated fetal CoA. Functionally, fetuses with a small aortic isthmus had low strain and strain rate of both the left and right ventricles at the time of diagnosis when compared to healthy controls, reflecting an impairment in systolic and diastolic ventricular function. An increase in the strain and strain rate of both ventricles was demonstrated in fetuses who underwent $\mathrm{CMH}$ compared to untreated fetuses with CoA, suggesting $\mathrm{CMH}$ led to an improvement in ventricular function. Furthermore, this increase in myocardial deformation (i.e., strain) was associated with increased combined ventricular output indexed to estimated fetal weight. These cardiac structural and functional findings support the concept of $\mathrm{MH}$ increases pulmonary venous return and provides the flow dynamics required to augment left-sided cardiac heart development in the setting of $\mathrm{CoA}$ and the underdeveloped left heart structures. Furthermore, oxygen therapy duration was associated with increased myocardial deformation, illustrating cardiac function is sensitive to oxygen therapy. This is possibly due to the improvement of cardiac structural development secondary to increased flow, the increase in myocardial contractility resulting from increased myocardial oxygen delivery (51), or both. Interestingly, within the oxygen therapy period, the largest increases in left cardiac dimensions and improvements in cardiac performance occurred during the first 4 weeks of administration, suggesting a critical window of intervention. Furthermore, the improvements in myocardial function when compared to cardiac structural dimensions had a closer resemblance to normal values at the end of the therapy, suggesting that myocardial mechanics may be more sensitive to oxygen therapy.

Lara et al. (50) investigated the effects of CMH (50\% $\mathrm{eFiO}_{2}$ for $>8$ hours/day) on fetuses with left heart hypoplasia $(\mathrm{LHH})$ and found improvements in aortic or mitral valvular dimensions albeit not statistically significant which was suggested to be limited by the small sample size. The authors found that oxygen intake over 9 hours per day was associated with improved aortic annular growth whereas the number of days on $\mathrm{MH}$ was not associated with any improvements in growth.

In summary, $\mathrm{CMH}$ is a promising therapeutic tool to improve left heart filling and provide the necessary flow dynamics needed to improve cardiac development in fetuses with left-sided CHD spanning from the mitral valve to the aortic isthmus. Based on the current studies, it appears $\mathrm{CMH}$ therapy administered early in the third trimester at $\sim 50 \% \mathrm{FiO}_{2}$ for at least 9 hours per day may be beneficial for left heart growth in fetuses with left sided-CHD. Furthermore, strict adherence to the therapy for the first 4 weeks may be recommended to have the best possible outcomes. 
The effects of $\mathrm{MH}$ on other cardiac defects such as aneurysm of the atrial septum (AAS) have been investigated. ASS is the malformation of septum primum resulting in a redundant and mobile atrial septal tissue. In severe cases, the septal tissue may excessively bulge into the left atrium during the cardiac cycle and impede flow across the mitral valve. As a result, fetal echocardiography may display a smaller and thin apex-forming LV with retrograde flow in the aortic arch. However, ASS is a relatively benign feature. After birth, the switch to switch to postnatal circulation causes an increase in pulmonary venous return which stabilizes the atrial septum and increases LV filling, eventually normalizing ventricular size (52). Channing et al. (52) recreated this phenomenon in utero by acute administration of $\mathrm{MH}\left(60 \% \mathrm{eFiO}_{2}\right.$ for 10 minutes). $\mathrm{AMH}$ led to a decrease in leftward bowing of the atrial septal excursion and increased roundness of the $L V$, suggesting improved LV filling whilst right ventricular dimensions remained unaffected. Furthermore, most of the subjects had a reversal in aortic isthmus flow from retrograde to antegrade flow. These findings further support the proof of concept $\mathrm{MH}$ has the potential to improve left ventricular structures by manipulating cardiac flow in utero.

Lastly, cardiac magnetic resonance (CMR) is a promising adjunct diagnostic tool to monitor the effects of $\mathrm{MH}$ therapy (9). CMR has the ability to non-invasively measure vessel blood flow, vessel blood oxygen saturation, and hematocrit levels to assess oxygen delivery, consumption, and extraction of the fetus in utero (53). In an imaging validation study, Porayette et al. (24) demonstrated that CMR identifies expected hemodynamic changes associated with $\mathrm{AMH}\left(70 \% \mathrm{eFiO}_{2}\right.$ for 10 minutes) reflected by an increase in pulmonary blood flow and decrease in DA flow in fetuses with CHD. Furthermore, umbilical vein oxygen saturation had a greater increase in fetuses with CHD when compared to healthy fetuses, suggesting fetuses with CHD may have baseline placental dysfunction. In a case study, Borik et al. (54) administered $\mathrm{AMH}\left(70 \% \mathrm{eFiO}_{2}\right.$ for 20 minutes) on a fetus with borderline LVH with a restrictive atrial septum and right-to-left shunt at $37 \mathrm{GW}$ assessed by CMR. Interestingly, AMH increased pulmonary blood flow but had no effect on aortic output and instead caused revered flow at the restrictive foramen ovale. The authors suggested AMH maybe not possible to increase left heart filling in fetuses with significant outflow tract obstruction. This illustrates that understanding the physiology and anatomy is important for $\mathrm{MH}$ candidacy as cases that have progressed to severe left outflow tract obstruction may not be practical.

\section{MH for fetal brain development in CHD}

Impaired cognitive, behavioural, and motor function is prevalent in children with CHD and is more severe as the complexity of CHD increases (4). Multiple factors are likely to contribute to neurodevelopmental abnormalities associated with CHD but brain injury during the operative and perioperative period is an important risk factor for the large majority of cases $(55,56)$. There is increasing evidence brain dysmaturation in fetuses with CHD has its origins during the fetal period (57-60) which predisposes the immature brain at birth to further injury during postnatal care $(58,61)$. The reduction in fetal brain oxygenation has been revealed in fetuses with CHD $(6,62)$, which has been associated with smaller fetal brain volumes (6). Severe forms of CHD are hypothesized to cause cerebral hypoxemia and/or hypoperfusion due to the nature of the cardiac lesions. The fetal brain has a protective autoregulatory mechanism to prevent the mismatch between cerebral metabolic supply and demand by increasing cerebral blood flow, as reflected by a decrease in cerebrovascular resistance (CR) upon ultrasound. However, this mechanism has been observed to be inadequate during the third trimester when there is a profound increase in metabolic demand to support accelerated brain growth (63). The prenatal diagnosis of critical CHD has been demonstrated to be a protective factor against postnatal brain injury, attributing to the early initiation of prostaglandin E1 to achieve a better hemodynamic state (64). Achieving a better hemodynamic state may be applied in utero whereby chronic administration of $\mathrm{MH}$ is anticipated to increase global oxygen saturations, increase aortic flow, or both. This is hypothesized to increase cerebral oxygen delivery back to normal and improve fetal brain growth.

Three studies have reported the use of AMH to assess the therapeutic role in alleviating cerebral hypoxemia (65-67). Due to the novelty of this concept, only one study has reported the use of $\mathrm{CMH}$ during the third trimester as a potential therapeutic tool to improve fetal brain growth in utero (68).

Szwast et al. (65) was the first to demonstrate the effects of $\mathrm{MH}$ on the cerebrovasculature in CHD, in particular a wide spectrum of HLHS variants. Administration of AMH $\left(60 \% \mathrm{eFiO}_{2}\right.$ for $>10$ minutes) revealed the cerebrovascular response in fetuses with HLHS was dependent on gestational age and baseline CR. The authors found the 
fetuses with lower the baseline middle cerebral artery (MCA) CR had a higher increase in CR in response to MH. This response pattern was hypothesized to reflect a greater normalization of cerebral blood flow which originally increased in response to the inadequate cerebral oxygen delivery to meet the cerebral metabolic demands. Moreover, the cerebrovasculature was only responsive to $\mathrm{MH}$ after 28 $\mathrm{GW}$, suggesting the cerebrovasculature is unable to sense oxygen before $28 \mathrm{GW}$ and the administration of $\mathrm{MH}$ before this time is not practical.

Hogan et al. (67) later demonstrated the structural anatomy and cardiovascular physiology in CHD plays an important role in cerebrovascular autoregulatory responses. Fetuses with left-sided obstructive lesions (LSOL) had the lowest CR in comparison to right-sided obstructive lesions (RSOL) and transposition of the great arteries (TGA). This CR pattern in fetuses with LSOL is likely due to both intracardiac mixing and decreased aortic output. Upon $\mathrm{AMH}\left(60 \% \mathrm{eFiO}_{2}\right.$ for $>10$ minutes), fetuses with LSOL had the least change in CR, especially fetuses demonstrating evidence of retrograde flow across the aortic arch. In LSOL with prograde flow, there was better improvement in CR but did not change as dramatically likely due to the low aortic output. LSOL is a spectrum of disease with different degrees of severity which may reflect the cerebrovascular responses to $\mathrm{MH}$. The lack of response in LSOL with retrograde flow may be attributed to the cerebral arteries at maximal vasodilatory capacity due to the low baseline cardiac output and relatively deoxygenated blood due to intra-cardiac mixing. The priority to protect perfusion pressure due to the low baseline cardiac output may override the vasoconstrictive effect of the cerebral arteries from the normalization of oxygen tension during MH. An alternative possibility is that fetuses with LSOL with retrograde flow at late gestation may have already adapted to the chronic hypoxic conditions. This is possibly explained by the decrease in cerebral basal metabolic demand to prioritize the available substrate necessary for cell survival and inhibiting non-essential metabolic activities (51). Unexpectedly, fetuses with RSOL had a cerebrovascular vasodilatory response to $\mathrm{AMH}$. This was hypothesized to be in response to a steal phenomenon from the pulmonary vasculature as a result of the decrease in pulmonary vascular resistance causing retrograde flow across the DA. These results suggest fetuses with RSOL have intact cerebrovascular autoregulation when compared to fetuses with LSOL.

You et al. (66) recently demonstrated AMH (70\%
$\mathrm{eFiO}_{2}$ from 0 to 6 minutes) resulted in an increase in brain oxygenation only in fetuses with single ventricle physiology (SVP) or aortic obstruction detected by blood oxygen level-dependent (BOLD) MRI. Moreover, the increase in brain oxygenation during the first 3 minutes of AMH was associated with increasing gestational age in fetuses with SVP. This may represent the need for a larger compensatory increase in cerebral oxygen delivery in response to the increasing mismatch between cerebral oxygen supply and demand, possibly due to the evolving nature of the cardiac defect or placental function. In contrast, two ventricle (TV) CHD and healthy fetuses had no change in brain oxygenation as gestation progressed. These findings suggest fetuses with SVP and aortic obstruction have lower baseline cerebral oxygen delivery whereas TV CHD and healthy fetuses are normal. Furthermore, the lack of increased brain oxygenation during AMH in TV CHD and healthy fetuses reflect the presence of an intact cerebrovascular regulatory system which illustrates that the required oxygen delivery to the brain is maintained in these fetuses.

In summary, these AMH studies on CHD reveals the cerebrovascular autoregulatory responsiveness to $\mathrm{AMH}$ is different in various forms of complex CHD which also depends on the severity of disease, baseline cerebrovascular autoregulatory capacity, and gestational age. Furthermore, severe forms of CHD such as SVP and aortic obstruction lesions appear to be the subtypes that may benefit from $\mathrm{MH}$ reflected by an increase in cerebral oxygenation when compared to TV CHD.

Edwards et al. (68) has been the only study to date to assess the effects of $\mathrm{CMH}$ in CHD. In a pilot cohort comprised of fetuses with $\mathrm{LHH}, \mathrm{CMH}\left(50 \% \mathrm{eFiO}_{2}\right.$ for $>8$ hours/day) resulted in a significant decrease in fetal biparietal diameter (BPD) growth over gestation and a smaller head circumference $Z$-score at 6 months. The reason behind this is unknown but the authors hypothesized $\mathrm{CMH}$ may have a negative effect on placental function and growth reflected by an increase in umbilical artery resistance and decrease in placental growth; however, both parameters were not significant. Although there was no apparent change in MCA CR, MH administration for greater than 9 hours per day had a positive effect on MCA CR, suggesting an improvement in cerebral oxygenation. Furthermore, a greater total number of weeks and hours on $\mathrm{MH}$ were associated with a greater increase in BPD. Based on these findings, the authors hypothesized the dosing and timing of $\mathrm{CMH}$ may be important. For example, intermittent oxygen delivery may be detrimental. In a fetal lamb study, $\mathrm{MH}$ 
caused a peak in pulmonary blood flow at 45 minutes which returned to baseline within 2 hours (69). If pulmonary blood flow normalization does occur, fetuses experiencing intermittent periods of increased oxygen tension could result in multiple periods of pulmonary and systemic vascular changes, which may negatively affect cerebral blood flow and impact head growth. Furthermore, this may worsen as gestation advances because the pulmonary vasculature seems to have a larger vasodilatory capacity (23), and thus, fetuses could experience a more profound change in the systemic and pulmonary circulation. Regardless, this pilot study highlighted the potential negative effects of $\mathrm{CMH}$ such that a larger randomized control trial must be performed to elucidate the risks and benefits of $\mathrm{CMH}$. This study has modified its protocol to longer daily exposure at a lower $\mathrm{eFiO}_{2}$ with fewer interruptions of $\mathrm{CMH}$ use. The possibility of $\mathrm{CMH}$ causing adverse effects on brain development has been also expressed by Rudolph (70). This was based on a fetal lamb study which found supraphysiologic oxygen ventilation $(100 \%$ $\mathrm{O}_{2}$ ) resulted in a reduction in cerebral blood flow which maintained cerebral oxygen delivery and consumption but significantly decreased cerebral glucose delivery and consumption (71). Furthermore, the lack of the majority of fetuses with elevated lactate CHD (57) suggests oxygen may not be the only limiting substrate.

\section{Safety and feasibility of MH}

Eight studies have investigated the use of $\mathrm{AMH}$ and found no safety concerns. Studies using AMH to assess for pulmonary vasculopathy $(31,32)$ found no adverse events to the mother or during the fetal and neonatal periods. In particular, there was no evidence of tricuspid regurgitation, DA constriction, fetal heart failure, abnormal placental function, or postnatal pulmonary hypertension due to $\mathrm{AMH}$. Studies assessing cardiac function in response to $\mathrm{AMH}$ found it safe and its effects were reversible on the fetal circulatory system (54) or did not report any adverse events $(52,72)$. Studies testing cerebrovascular response to AMH did not report any adverse events (65-67).

Six studies that have investigated the use of $\mathrm{CMH}$ to improve left-sided heart growth did not find or report adverse events during the fetal and neonatal periods or of the mother (46-50). In particular, there was no evidence of disrupted placental function, fetal cardiac failure, premature DA constriction, postnatal pulmonary hypertensive events, or retinopathy of prematurity (i.e., fetuses had complete retinal vascularization) due to $\mathrm{CMH}$. No abnormal maternal chest X-rays were reported. Lara et al. (50) expressed a potential concern for the possibility of delayed fetal growth caused by $\mathrm{CMH}$ therapy but this finding could have been confounded by a small sample size composed of fetuses with LHH. However, Zeng et al. (49) found a significant increase in birth weight in a larger cohort in fetuses with $\mathrm{CoA}$ after $\mathrm{CMH}$ therapy. Edwards et al. (68) found a potential negative impact on brain growth and placental growth and function but this finding could have also been confounded by a small sample size composed of fetuses with LHH. Nonetheless, this is a concern because smaller head circumference at birth and during infancy is an important risk factor for later intelligence $(73,74)$. The authors have since cautioned the use of $\mathrm{CMH}$, have informed the participants of this concern, and have changed their protocol.

Epistaxis has been reported in mothers on oxygen therapy (50) which was resolved with a humidifier attachment to the oxygen condensing units. Otherwise, $\mathrm{AMH}$ or $\mathrm{CMH}$ appears feasible for pregnant mothers.

\section{Future directions}

The therapeutic potential of $\mathrm{CMH}$ based on fetal flow manipulation is promising to improve left heart growth in fetuses with evolving LVH and the associated hypoplastic left heart structures. Other forms of CHD such as rightsided SVP may benefit from CMH to improve cardiac growth. However, it would be interesting to explore whether the duration of $\mathrm{MH}$-induced pulmonary vasodilatation affects the normalization of pulmonary blood flow. If so, are periods of intermittent oxygenation more beneficial for left-sided cardiac growth? Nevertheless, the dose and duration of $\mathrm{MH}$ used to improve fetal heart growth may not be appropriate for fetal brain development. The frequent changes to the systemic and pulmonary blood flow may have negative consequences on the brain. Further studies will need to elucidate the different effects of intermittent and uninterrupted administration of $\mathrm{CMH}$ on fetal heart growth and brain development. This is particularly important in fetuses with evolving LVH where the fetal heart and brain may be impacted simultaneously. The recent advancements in fetal CMR can help further our understanding of the fetal circulatory changes in $\mathrm{AMH}$ and CMH. CMR provides the ability to assess fetal and cerebral oxygen delivery, consumption, and extraction. When compared with MRI brain volumetry, this provides a unique opportunity to assess the relationship between 
Table 2 Current investigations of maternal hyperoxygenation in congenital heart disease

\begin{tabular}{lllllll}
\hline $\begin{array}{l}\text { ClinicalTrials.gov } \\
\text { identifier }\end{array}$ & Diagnosis & $\begin{array}{l}\text { Oxygen } \\
\text { delivery }\end{array}$ & Study design & $\begin{array}{l}\text { Estimated } \\
\text { enrollment }\end{array}$ & Status & Objectives \\
\hline NCT02965638 & LHH & Chronic MH & Interventional & 12 & Recruiting & $\begin{array}{l}\text { Improve cardiac and brain } \\
\text { growth }\end{array}$ \\
NCT03147014 & $\begin{array}{l}\text { HLHS, aortic coarctation, } \\
\text { atrial septal aneurysm }\end{array}$ & Acute MH & Interventional & 600 & Recruiting & $\begin{array}{l}\text { Characterize the hemodynamic } \\
\text { effects by Doppler ultrasound }\end{array}$ \\
NCT03136835 & HLHS & Chronic MH & Interventional & 20 & Recruiting & Safety and feasibility \\
NCT03771534 & TGA & Acute MH & Interventional & 50 & Recruiting & $\begin{array}{l}\text { Characterize the hemodynamic } \\
\text { effects by MRI } \\
\text { NCT03944837 }\end{array}$ \\
& CHD & Acute MH & Interventional & 170 & Recruiting & $\begin{array}{l}\text { Characterize the hemodynamic } \\
\text { effects by MRI }\end{array}$ \\
\hline
\end{tabular}

LHH, left heart hypoplasia; HLHS, hypoplastic left heart syndrome; TGA, transposition of the great arteries; CHD, congenital heart disease; $\mathrm{MH}$, maternal hyperoxygenation.

human fetal hemodynamics and brain development (9). Furthermore, novel magnetic resonance techniques such as chemical exchange saturation transfer imaging (CEST) is a promising tool to assess other substrates, such as glucose uptake and metabolism in fetal organs $(75,76)$ which has already proven feasible in the placenta (77). Table 2 lists the current ongoing studies investigating the use of $\mathrm{MH}$ in CHD.

\section{Conclusions}

In the recent years, $\mathrm{MH}$ has been investigated as a diagnostic tool and therapeutic agent in CHD with a focus on left-sided cardiac defects to improve developmental outcomes. These patients have a poor prognosis and have an increased risk for comorbidities such as pulmonary vasculopathy and delayed fetal brain growth. AMH appears to be a useful provocative tool to improve treatment strategies by detecting signs of pulmonary vasculopathy in HLHS fetuses with a high suspicion of a restrictive or intact atrial septum. Furthermore, AMH can be used to assess the short-term changes of left-sided heart filling and cerebral oxygenation in left-sided CHD. Based on the current evidence, $\mathrm{CMH}$ is a promising therapeutic tool to improve left heart growth in fetuses with left-sided CHD spanning from the mitral valve to the aortic isthmus. However, the therapeutic potential of $\mathrm{CMH}$ to improve fetal brain growth in fetuses with left-sided CHD needs further investigation.

\section{Acknowledgments}

Funding: None.

\section{Footnote}

Provenance and Peer Review: This article was commissioned by the Guest Editor (Antonio F. Corno) for the series "Prenatal Diagnosis in Congenital Heart Defects" published in Translational Pediatrics. The article has undergone external peer review.

Conflicts of Interest: The authors have completed the ICMJE uniform disclosure form (available at http://dx.doi. org/10.21037/tp-20-226). The series "Pre-natal Diagnosis in Congenital Heart Defects" was commissioned by the editorial office without any funding or sponsorship. The authors have no other conflicts of interest to declare.

Ethical Statement: The authors are accountable for all aspects of the work in ensuring that questions related to the accuracy or integrity of any part of the work are appropriately investigated and resolved.

Open Access Statement: This is an Open Access article distributed in accordance with the Creative Commons Attribution-NonCommercial-NoDerivs 4.0 International License (CC BY-NC-ND 4.0), which permits the non- 
commercial replication and distribution of the article with the strict proviso that no changes or edits are made and the original work is properly cited (including links to both the formal publication through the relevant DOI and the license). See: https://creativecommons.org/licenses/by-nc-nd/4.0/.

\section{References}

1. van der Linde D, Konings EEM, Slager MA, et al. Birth prevalence of congenital heart disease worldwide: $\mathrm{A}$ systematic review and meta-analysis. J Am Coll Cardiol 2011;58:2241-7.

2. Oster ME, Lee KA, Honein MA, et al. Temporal Trends in Survival Among Infants With Critical Congenital Heart Defects. Pediatrics 2013;131:e1502-8.

3. Best KE, Rankin J. Long-term survival of individuals born with congenital heart disease: A systematic review and meta-analysis. J Am Heart Assoc 2016;5:1-16.

4. Marino BS, Lipkin PH, Newburger JW, et al.

Neurodevelopmental outcomes in children with congenital heart disease: Evaluation and management a scientific statement from the american heart association. Circulation 2012;126:1143-72.

5. Rudolph AM. Congenital cardiovascular malformations and the fetal circulation. Arch Dis Child Fetal Neonatal Ed 2010;95:F132-6.

6. Sun L, Macgowan CK, Sled JG, et al. Reduced Fetal Cerebral Oxygen Consumption is Associated With Smaller Brain Size in Fetuses With Congenital Heart Disease. Circulation 2015;131:1313-23.

7. Cercignani M, Bouyagoub S. Brain microstructure by multi-modal MRI: is the whole greater than the sum of its parts? Neuroimage 2018;182:117-27.

8. Mailath-Pokorny M, Kasprian G, Mitter C, et al. Magnetic resonance methods in fetal neurology. Semin Fetal Neonatal Med 2012;17:278-84.

9. Marini D, van Amerom J, Saini BS, et al. MR imaging of the fetal heart. J Magn Reson Imaging 2020;51:1030-44.

10. Brantberg A, Sonesson SE. Central arterial hemodynamics in small-for-gestational-age fetuses before and during maternal hyperoxygenation: A Doppler velocimetric study with particular attention to the aortic isthmus. Ultrasound Obstet Gynecol 1999;14:237-43.

11. Done E, Allegaert K, Lewi P, et al. Maternal hyperoxygenation test in fetuses undergoing FETO for severe isolated congenital diaphragmatic hernia. Ultrasound Obstet Gynecol 2011;37:264-71.
12. Caforio L, Caruso A, Testa AC, et al. Short-term maternal oxygen administration in fetuses with absence or reversal of end-diastolic velocity in umbilical artery: Pathophysiological and clinical considerations. Acta Obstet Gynecol Scand 1998;77:707-11.

13. Rizzo G, Arduini D, Romanini C, et al. Doppler echocardiographic assessment of time to peak velocity in the aorta and pulmonary artery of small for gestational age fetuses. Br J Obstet Gynaecol 1990;97:603-7.

14. de Rochambeau B, Poix D, Mellier G. Maternal hyperoxygenation: a fetal blood flow velocity prognosis test in small-for-gestational-age fetuses? Ultrasound Obstet Gynecol 1992;2:279-82.

15. Broth RE, Wood DC, Rasanen J, et al. Prenatal prediction of lethal pulmonary hypoplasia: The hyperoxygenation test for pulmonary artery reactivity. Am J Obstet Gynecol 2002;187:940-5.

16. Say L, Gülmezoglu AM, Hofmeyr GJ. Maternal oxygen administration for suspected impaired fetal growth. Cochrane Database Syst Rev 2003;(1):CD000137.

17. Rudolph AM. Impaired cerebral development in fetuses with congenital cardiovascular malformations: Is it the result of inadequate glucose supply? Pediatr Res 2016;80:172-7.

18. Schrauben EM, Saini BS, Darby JRT, et al. Fetal hemodynamics and cardiac streaming assessed by $4 \mathrm{D}$ flow cardiovascular magnetic resonance in fetal sheep. J Cardiovasc Magn Reson 2019;21:8.

19. Hickey EJ, Caldarone CA, McCrindle BW. Left ventricular hypoplasia: A spectrum of disease involving the left ventricular outflow tract, aortic valve, and aorta. J Am Coll Cardiol 2012;59:S43-54.

20. Levin DL, Heymann MA, Rudolph AM. Morphological development of the pulmonary vascular bed in experimental pulmonic stenosis. Circulation 1979;59:179-82.

21. Gao Y, Cornfield DN, Stenmark KR, et al. Unique aspects of the developing lung circulation: Structural development and regulation of vasomotor tone. Pulm Circ 2016;6:407-25.

22. Enzensberger C, Tenzer A, Degenhardt J, et al. Pulmonary vasoreactivity to materno-fetal hyperoxygenation in fetuses with hypoplastic left heart. 23rd World Congr Ultrasound Obstet Gynecol 2013;3:715-8.

23. Rasanen J, Wood DC, Debbs RH, et al. Reactivity of the human fetal pulmonary circulation to maternal hyperoxygenation increases during the second half 
of pregnancy: A randomized study. Circulation 1998;97:257-62.

24. Porayette P, Madathil S, Sun L, et al. MRI reveals hemodynamic changes with acute maternal hyperoxygenation in human fetuses with and without congenital heart disease. Prenat Diagn 2016;36:274-81.

25. Rychik J, Rome JJ, Collins MH, et al. The hypoplastic left heart syndrome with intact atrial septum: Atrial morphology, pulmonary vascular histopathology and outcome. J Am Coll Cardiol 1999;34:554-60.

26. Abman SH, Accurso FJ. Acute effects of partial compression fetal pulmonary circulation of ductus arteriosus on fetal pulmonary circulation 1989;257:H626-34.

27. Reddy VM, Meyrick B, Wong J, et al. In utero placement of aortopulmonary shunts. A model of postnatal pulmonary hypertension with increased pulmonary blood flow in lambs. Circulation 1995;92:606-13.

28. Reddy VM, Wong J, Liddicoat JR, et al. Altered endothelium-dependent responses in lambs with pulmonary hypertension and increased pulmonary blood flow. Am J Physiol - Hear Circ Physiol 1996;271:H565-70.

29. Graziano JN, Heidelberger KP, Ensing GJ, et al. The influence of a restrictive atrial septal defect on pulmonary vascular morphology in patients with hypoplastic left heart syndrome. Pediatr Cardiol 2002;23:146-51.

30. Cheatham JP. Intervention in the critically ill neonate and infant with hypoplastic left heart syndrome and intact atrial septum. J Interv Cardiol 2001;14:357-66.

31. Szwast A, Tian Z, McCann M, et al. Vasoreactive response to maternal hyperoxygenation in the fetus with hypoplastic left heart syndrome. Circ Cardiovasc Imaging 2010;3:172-8.

32. Enzensberger C, Axt-Fliedner R, Degenhardt J, et al. Pulmonary vasoreactivity to materno-fetal hyperoxygenation testing in fetuses with hypoplastic left heart. Ultraschall Med 2016;37:195-200.

33. Taketazu M, Barrea C, Smallhorn JF, et al. Intrauterine pulmonary venous flow and restrictive foramen ovale in fetal hypoplastic left heart syndrome. J Am Coll Cardiol 2004;43:1902-7.

34. Michelfelder E, Gomez C, Border W, et al. Predictive value of fetal pulmonary venous flow patterns in identifying the need for atrial septoplasty in the newborn with hypoplastic left ventricle. Circulation 2005;112:2974-9.

35. Better DJ, Apfel HD, Zidere V, et al. Pattern of pulmonary venous blood flow in the hypoplastic left heart syndrome in the fetus. Heart 1999;81:646-9.

36. Marshall AC, Van Der Velde ME, Tworetzky W, et al. Creation of an atrial septal defect in utero for fetuses with hypoplastic left heart syndrome and intact or highly restrictive atrial septum. Circulation 2004;110:253-8.

37. Kalish BT, Tworetzky W, Benson CB, et al. Technical challenges of atrial septal stent placement in fetuses with hypoplastic left heart syndrome and intact atrial septum. Catheter Cardiovasc Interv 2014;84:77-85.

38. Marshall AC, Levine J, Morash D, et al. Results of in utero atrial septoplasty in fetuses with hypoplastic left heart syndrome Audrey. Prenat Diagn 2008;28:1023-8.

39. Pundi KN, Johnson JN, Dearani JA, et al. 40-year followup after the fontan operation long-term outcomes of 1,052 patients. J Am Coll Cardiol 2015;66:1700-10.

40. Javed R, Cetta F, Said SM, et al. Hypoplastic left heart syndrome: an overview for primary care providers. Pediatr Rev 2019;40:344-53.

41. Allan LD, Sharland G, Tynan MJ. The natural history of the hypoplastic left heart syndrome. Int J Cardiol 1989;25:341-3.

42. Gardiner HM. Response of the fetal heart to changes in load: from hyperplasia to heart failure. Heart 2005;91:871-3.

43. Siewers RD, Ettedgui J, Pahl E, et al. Coarctation and hypoplasia of the aortic arch: Will the arch grow? Ann Thorac Surg 1991;52:608-13.

44. Rudolph AM, Heymann MA, Spitznas U. Hemodynamic considerations in the development of narrowing of the aorta. Am J Cardiol 1972;30:514-25.

45. Feinstein JA, Benson DW, Dubin AM, et al. Hypoplastic left heart syndrome: Current considerations and expectations. J Am Coll Cardiol 2012;59:S1-42.

46. Kohl T. Chronic intermittent materno-fetal hyperoxygenation in late gestation may improve on hypoplastic cardiovascular structures associated with cardiac malformationsin human fetuses. Pediatr Cardiol 2010;31:250-63.

47. Kohl T. Effects of maternal-fetal hyperoxygenation on aortic arch flow in a late-gestation human fetus with closed oval foramen at risk for coarctation. J Thorac Cardiovasc Surg 2011;142:e67-9.

48. Zeng S, Zhou J, Peng Q, et al. Sustained maternal hyperoxygenation improves aortic arch dimensions in fetuses with coarctation. Sci Rep 2016;6:39304.

49. Zeng S, Zhou J, Peng Q, et al. Sustained chronic maternal hyperoxygenation increases myocardial deformation in 
fetuses with a small aortic isthmus at risk for coarctation. J Am Soc Echocardiogr 2017;30:992-1000.

50. Lara DA, Morris SA, Maskatia SA, et al. Pilot study of chronic maternal hyperoxygenation and effect on aortic and mitral valve annular dimensions in fetuses with left heart hypoplasia. Ultrasound Obstet Gynecol 2016;48:365-72.

51. Wheaton WW, Chandel NS. Hypoxia. 2. Hypoxia regulates cellular metabolism. Am J Physiol Cell Physiol 2011;300:C385-C393.

52. Channing A, Szwast A, Natarajan S, et al. Maternal hyperoxygenation improves left heart filling in fetuses with atrial septal aneurysm causing impediment to left ventricular inflow. Ultrasound Obstet Gynecol 2015;45:664-9.

53. Sun L, Marini D, Saini B, et al. Understanding fetal hemodynamics using cardiovascular magnetic resonance imaging. Fetal Diagn Ther 2020;47:354-62.

54. Borik S, Macgowan CK, Seed M. Maternal hyperoxygenation and foetal cardiac MRI in the assessment of the borderline left ventricle. Cardiol Young 2015;25:1214-7.

55. Morton PD, Ishibashi N, Jonas RA. Neurodevelopmental Abnormalities and Congenital Heart Disease: Insights into Altered Brain Maturation. Circ Res 2017;120:960-77.

56. Claessens NHP, Algra SO, Ouwehand TL, et al. Perioperative neonatal brain injury is associated with worse school-age neurodevelopment in children with critical congenital heart disease. Dev Med Child Neurol 2018;60:1052-8.

57. Limperopoulos C, Tworetzky W, McElhinney DB, et al. Brain volume and metabolism in fetuses with congenital heart disease: Evaluation with quantitative magnetic resonance imaging and spectroscopy. Circulation 2010;121:26-33.

58. Claessens NHP, Khalili N, Isgum I, et al. Brain and CSF volumes in fetuses and neonates with antenatal diagnosis of critical congenital heart disease: A longitudinal MRI study. Am J Neuroradiol 2019;40:885-91.

59. Jørgensen DE, Tabor A, Rode L, et al. Longitudinal brain and body growth in fetuses with and without transposition of the great arteries: Quantitative volumetric magnetic resonance imaging study. Circulation 2018;138:1368-70.

60. Ortinau CM, Rollins CK, Gholipour A, et al. EarlyEmerging Sulcal Patterns Are Atypical in Fetuses with Congenital Heart Disease. Cereb Cortex 2019;29:3605-16.

61. Brossard-Racine M, Du Plessis A, Vezina G, et al. Brain injury in neonates with complex congenital heart disease: what is the predictive value of mri in the fetal period? Am J Neuroradiol 2016;37:1338-46.

62. Lauridsen MH, Uldbjerg N, Henriksen TB, et al. Cerebral oxygenation measurements by magnetic resonance imaging in fetuses with and without heart defects. Circ Cardiovasc Imaging 2017;10:e06459.

63. Hahn E, Szwast A, Cnota J, et al. Association between fetal growth, cerebral blood flow and neurodevelopmental outcome in univentricular fetuses. Ultrasound Obstet Gynecol 2016;47:460-5.

64. Peyvandi S, De Santiago V, Chakkarapani E, et al. Association of prenatal diagnosis of critical congenital heart disease with postnatal brain development and the risk of brain injury. JAMA Pediatr 2016;170:e154450.

65. Szwast A, Putt M, Gaynor JW, et al. Cerebrovascular response to maternal hyperoxygenation in fetuses with hypoplastic left heart syndrome depends on gestational age and baseline cerebrovascular resistance. Ultrasound Obstet Gynecol 2018;52:473-8.

66. You W, Andescavage NN, Kapse K, et al. Hemodynamic responses of the placenta and brain to maternal hyperoxia in fetuses with congenital heart disease by using blood oxygen-level dependent MRI. Radiology 2020;294:141-8.

67. Hogan WJ, Moon-Grady AJ, Zhao Y, et al. Fetal cerebral vascular response to maternal hyperoxia in congenital heart disease: effects of cardiac physiology. Ultrasound Obstet Gynecol 2020. [Epub ahead of print].

68. Edwards LA, Lara DA, Sanz Cortes M, et al. Chronic maternal hyperoxygenation and effect on cerebral and placental vasoregulation and neurodevelopment in fetuses with left heart hypoplasia. Fetal Diagn Ther 2019;46:45-57.

69. Accurso FJ, Alpert B, Wilkening RB, et al. Timedependent response of fetal pulmonary blood flow to an increase in fetal oxygen tension. Respir Physiol 1986;63:43-52.

70. Rudolph AM. Maternal hyperoxygenation for the human fetus: should studies be curtailed? Pediatr Res 2020;87:630-3.

71. Iwamoto HS, Teitel DF, Rudolph AM. Effect of birthrelated events on metabolism in fetal sheep. Pediatr Res 1991;30:158-64.

72. Porayette P, van Amerom JF, Yoo SJ, et al. MRI shows limited mixing between systemic and pulmonary circulations in foetal transposition of the great arteries: a potential cause of in utero pulmonary vascular disease. Cardiol Young 2015;25:737-44.

73. Lundgren EM, Cnattingius S, Jonsson B, et al. Intellectual and psychological performance in males born small for 
gestational age. Pediatr Res 2001;50:91-6.

74. Gale CR, O'Callaghan FJ, Bredow M, et al. The influence of head growth in fetal life, infancy, and childhood on intelligence at the ages of 4 and 8 years. Pediatrics 2006;118:1486-92.

75. Wang J, Weygand J, Hwang KP, et al. Magnetic resonance imaging of glucose uptake and metabolism in patients with head and neck cancer. Sci Rep 2016;6:30618.

Cite this article as: Lee FT, Marini D, Seed M, Sun L. Maternal hyperoxygenation in congenital heart disease. Transl Pediatr 2021;10(8):2197-2209. doi: 10.21037/tp-20-226
76. Colgan N, Donoghue M, Zuchora Z, et al. Investigation of GlucoCEST as novel clinical MR biomarker of glucose metabolism. Phys Medica 2016;32:959.

77. Luo J, Turk EA, Gagoski B, et al. Preliminary evaluation of dynamic glucose enhanced MRI of the human placenta during glucose tolerance test. Quant Imaging Med Surg 2019;9:1619-27. 